University of Nebraska - Lincoln

DigitalCommons@University of Nebraska - Lincoln

Papers in Veterinary and Biomedical Science

Veterinary and Biomedical Sciences,

Department of

June 2002

\title{
Phylogenetic analysis of Brazilian bovine viral diarrhea virus type 2 (BVDV-2) isolates: evidence for a subgenotype within BVDV-2
}

\author{
Eduardo F. Flores \\ Universidade Federal de Santa Maria, 97105 -900 Santa Maria RS, Brazil \\ Julia F. Ridpath \\ USDA, Agricultural Research Service, Ames, IA \\ Rudi Weiblen \\ Universidade Federal de Santa Maria, 97105 -900 Santa Maria RS, Brazil \\ Fernanda S. F. Vogel \\ Universidade Federal de Santa Maria, 97105 -900 Santa Maria RS, Brazil \\ Laura H.V.G. Gil \\ University of Nebraska - Lincoln
}

Follow this and additional works at: https://digitalcommons.unl.edu/vetscipapers

Part of the Veterinary Medicine Commons

Flores, Eduardo F.; Ridpath, Julia F.; Weiblen, Rudi; Vogel, Fernanda S. F.; and Gil, Laura H.V.G., "Phylogenetic analysis of Brazilian bovine viral diarrhea virus type 2 (BVDV-2) isolates: evidence for a subgenotype within BVDV-2" (2002). Papers in Veterinary and Biomedical Science. 89.

https://digitalcommons.unl.edu/vetscipapers/89

This Article is brought to you for free and open access by the Veterinary and Biomedical Sciences, Department of at DigitalCommons@University of Nebraska - Lincoln. It has been accepted for inclusion in Papers in Veterinary and Biomedical Science by an authorized administrator of DigitalCommons@University of Nebraska - Lincoln. 


\title{
Phylogenetic analysis of Brazilian bovine viral diarrhea virus type 2 (BVDV-2) isolates: evidence for a subgenotype within BVDV-2
}

\author{
Eduardo F. Flores a,*, Julia F. Ridpath b, Rudi Weiblen a, \\ Fernanda S.F. Vogel ${ }^{\text {a }}$, Laura H.V.G. Gil ${ }^{\mathrm{c}}$ \\ a Departamento de Medicina Veterinária Preventiva e Departamento de Microbiologia e Parasitologia, \\ Universidade Federal de Santa Maria, 97105-900 Santa Maria RS, Brazil \\ ${ }^{\mathrm{b}}$ Virus and Prion Diseases of Livestock Research Unit, National Animal Disease Center, USDA, Agricultural Research Service, \\ Ames, IA 50010, USA \\ ' Department of Veterinary and Biomedical Sciences, University of Nebraska at Lincoln, Lincoln, NE 68583-0905, USA
}

Received 17 July 2001; received in revised form 9 April 2002; accepted 16 April 2002

\begin{abstract}
Phylogenetic analysis divides bovine viral diarrhea viruses (BVDV) into two different genotypes (BVDV1 and BVDV2). BVDV1 strains have been further subdivided into two to 11 subgenotypes. Phylogenetic analysis of BVDV2 isolates, however, has not been able to identify discrete subgenotypes. In this study, we identified six South American BVDV2 strains and one North American BVDV2 strain that cluster to a separate genetic group within BVDV2, thus representing a distinct subgenotype. The $5^{\prime}$ untranslated region (UTR) sequence homology between these six strains and other BVDV2 from North America, Europe and Asia (81.7\%) is lower than the homology used to segregate BVDV1 into BVDV1a and BVDV1b (83.6\%). Most nucleotide differences observed between the two subgroups of BVDV2 were concentrated in two regions, which also harbor most of the differences seen between BVDV1a and BVDV1b. To determine if this segregation was real, an additional analysis was performed comparing NS2/3 sequences. Analysis of a conserved sequence located between nucleotides 6670 and 7186 of the NS2/3 coding region also segregated these isolates to a separate group. The sequence homology between the two subgroups $(86.3 \%)$ was higher than the homology in the $5^{\prime}$ UTR $(81.7 \%)$, with mean sequence homologies of 91 and $87.2 \%$ within the proposed subgroups. In contrast to the $5^{\prime} \mathrm{UTR}$, alignment of the NS2/3 sequences revealed nucleotide differences distributed across the region. These results demonstrate that BVDV2 isolates cluster to two genetically distinct subgroups within BVDV2. The differences in both the 5'UTR and NS2/3 are consistent and justify this segregation. We suggest that BVDV2 may thereafter be subgenotyped into BVDV2a and BVDV2b. The existence of subgroups within the BVDV2 genotype with genetic heterogeneity similar to that seen among BVDV1 subgroups argues against BVDV2 isolates arising from BVDV1 in a recent evolutionary event. Unless the evolutionary clocks for BVDV1 and
\end{abstract}

* Corresponding author. Tel.: + 55-55-220-8055; fax: + 55-55-220-8034

E-mail address: flores@ccr.ufsm.br (E.F. Flores). 
BVDV2 isolates tick along at different rates, these results indicate that BVDV2 have existed as long as BVDV1. (C) 2002 Elsevier Science B.V. All rights reserved.

Keywords: Bovine viral diarrhea virus; Bovine pestivirus; Pestivirus genotypes

\section{Introduction}

Bovine viral diarrhea virus (BVDV) is ubiquitous among cattle and has been associated with significant losses to the livestock industry worldwide. BVDV is a small enveloped RNA virus belonging to the family Flaviviridae, genus Pestivirus, along with classical swine fever virus (CSFV) and border disease virus (BDV) of sheep (Francki et al., 1991). BVDV infection of seronegative cattle may result in a variety of clinical manifestations, ranging from inapparent infections to the severe acute BVD (Corapi et al., 1989) and the fatal mucosal disease (Baker, 1995). Infection of pregnant cows is often associated with reproductive losses, including embryonic or fetal deaths, abortions, congenital malformations, stillbirths and the birth of immunotolerant, persistently viremic calves (Moennig and Liess, 1995).

The BVDV genome is a linear, single stranded positive-sense RNA molecule of approximately $12.5 \mathrm{~kb}$. The viral genome contains a single large open reading frame (ORF) encoding a polyprotein of approximately 3900 amino acids. The ORF is preceded by an untranslated region ( $5^{\prime} \mathrm{UTR}$ ) of 381-386 nucleotides (nt) whose sequence is highly conserved among pestiviruses (Collett et al., 1988; Deng and Brock, 1993). The sequence variations within the $5^{\prime} \mathrm{UTR}$ have been exploited to study the genetic relationships among BVDV isolates. Phylogenetic analysis based on the 5'UTR has allowed the segregation of BVDV into two genotypes: BVDV1 and BVDV2 (Pellerin et al., 1994; Ridpath et al., 1994; Wolfmeyer et al., 1997). BVDV1 isolates can be further divided in two subgenotypes: BVDV1a and BVDV1b (Pellerin et al., 1994). The phylogenetic segregation correlates with antigenic differences between these groups of viruses: BVDV1 isolates display a reduced serological cross-reactivity with BVDV2 (Ridpath et al., 1994; Wolfmeyer et al., 1997). Recently, a further subdivision of BVDV1 into 11 subgenotypes has been proposed (Vilcek et al., 2001).
The BVDV1 genotype includes most viruses commonly used for vaccine production, laboratory diagnosis and research (Ridpath et al., 1994). Viruses belonging to the BVDV2 group were initially identified in severe outbreaks of acute BVD in North America in the late 1980s (Corapi et al., 1989; Carman et al., 1998). The origin and evolution of BVDV2 is still a matter of dispute. Initially thought to be new and invariably highly virulent viruses, BVDV2 isolates have been shown to be circulating among North American cattle for at least 20 years (Carman, 1995). Likewise, the BVDV2 genotype does not always correlate with high virulence. A large number of BVDV2 isolates have originated from sources other than animals with severe disease (Ridpath et al., 1994; Wolfmeyer et al., 1997; Bolin and Ridpath, 1998).

Although BVDV2s have been mainly identified in the US and Canada, several articles have reported their presence in Europe (Van Rijn et al., 1997; Wolfmeyer et al., 1997; Vilcek et al., 2001), South America (Canal et al., 1998; Gil et al., 1998) and Japan (Nagai et al., 1998). In a recent article, we described the main clinical, pathological and antigenic aspects associated with BVDV2 isolates recently identified in Brazil (Flores et al., 2000). Preliminary phylogenetic data suggested that these isolates were genetically distinct from the North American BVDV2. In the present study, we describe a further phylogenetic analysis of Brazilian BVDV2, providing evidence that these viruses cluster into a distinct subgenotype within BVDV2.

\section{Material and methods}

\subsection{Cell culture and viruses}

The origin and antigenic characterization of four Brazilian BVDV2 isolates (VS-260, LV-96, VS-63 and VS-123.4) have been reported previously (Flores et al., 2000). The North American 
BVDV isolates analyzed originated in the US or Canada and were isolated between 1960 and 1998 (Ridpath et al., 2000). Laboratory, vaccine strains and field isolates are included. All viruses were biologically cloned by serial passage and limiting dilution. The cultured cells (Madin-Darby bovine kidney (MDBK) or bovine turbinate (BT)) used for virus propagation and the serum used for cell growth were tested and found free of pestivirus contamination. The sequences of the Brazilian isolate BVDV2 Soldan (Accession No. U94914); Argentinean BVDV2 34B (AF244952); Asian BVDV2-OY89 (AB003621) and BVDV2-SW90 (AB003622); and European BVDV2-167237 (U65055) and BVDV2-97/730 (AF026770) were obtained from the Genbank.

\subsection{Viral RNA amplification, $c D N A$ sequencing and phylogenetic analysis}

Genotyping of Brazilian BVDV isolates was based on phylogenetic analysis of two highly conserved sequences in the viral genome: the $5^{\prime} \mathrm{UTR}$ and the NS2/3 coding region. Total RNA was extracted from cells infected with each isolate and viral sequences were amplified by PCR according to protocols described previously (Ridpath and Bolin, 1998). The amplicons were subsequently submitted to nucleotide (nt) sequencing. The first analyzed region was a $268 \mathrm{nt}$ sequence located within the $5^{\prime}$ untranslated region (UTR) of the viral genome. Sequences from the 5'UTR were amplified as described (Ridpath and Bolin, 1998). The second analyzed sequence is located within the coding region of the non-structural viral polypeptide NS2/3 and was amplified using the primers 5'GGC AGT CAC AAT AGG AG 3' (forward primer, position 6625) and 5'TTG CCT GAG TCC GAC CA 3' (reverse primer, position 7186). The primer positions correspond to the sequence of the reference BVDV strain SD-1 (Deng and Brock, 1992). The PCR conditions and sequencing reactions have been described earlier (Ridpath et al., 1994; Ridpath and Bolin, 1998). Both strands of each PCR product were sequenced in duplicate. Comparison and analysis of derived sequences was performed using the Align Plus (Scientific and Educational Software, State
Line, PA), GeneWorks (Intelligenetics Inc., Mountain View, CA), MacDNASIS (Hitachi Software, San Bruno, CA) software packages and MEGA (Pennsylvania State University, University Park, PA).

\section{Results}

\subsection{Sequence analysis of the $5^{\prime} U T R$}

Among 23 Brazilian isolates of BVDV previously submitted to phylogenetic analysis based on the 5'UTR, four (VS-260, VS-63, LV-96 and VS123.4) were classified as BVDV2 (Gil et al., 1998). The mean sequence homology among the 5'UTR of these isolates was $91.3 \%$ using an unpaired geometric mean analysis (UPGMA) (HigginsSharp algorithm/CLUSTAL4, MacDNASIS software package). When the $5^{\prime} \mathrm{UTR}$ of these four isolates were compared to sequences of 30 other BVDV2 sequences available from GenBank or derived from BVDV2 submitted to the NADC, two distinct subgroups were apparent (Fig. 1). One subgroup (BVDV2b) contained these four Brazilian BVDV2s, a BVDV2 isolated in Brazil a few years earlier (Soldan), an Argentinean BVDV2 isolate (34B) and one North American BVDV2 (28508-5). The remaining 23 North American BVDV2 s, the two Asian BVDV2s (BVDV2-OY89 and BVDV2-SW90) and the two European BVDV2s (BVDV2-167237 and BVDV297/730) made up the other subgroup (BVDV2a). The sequence homology between these two subgroups was calculated to be $81.7 \%$ using the CLUSTAL4 analysis method (MacDNASIS). The calculated sequence homology between the BVDV1a and BVDV1b subgenotypes using the same analysis was 83.3\% (CLUSTAL4 analysis performed using the reference BVDV1a and BVDV1b strains shown in Fig. 1). Most nucleotide differences observed between the two subgroups of BVDV2 were concentrated in two regions: a $19 \mathrm{nt}$ sequence located between nucleotides 210 and 229; and a $20 \mathrm{nt}$ sequence located between nt 305 and 325 of the 5'UTR (Fig. 2). Interestingly, these regions also harbor most of the differences seen between BVDV1a and 


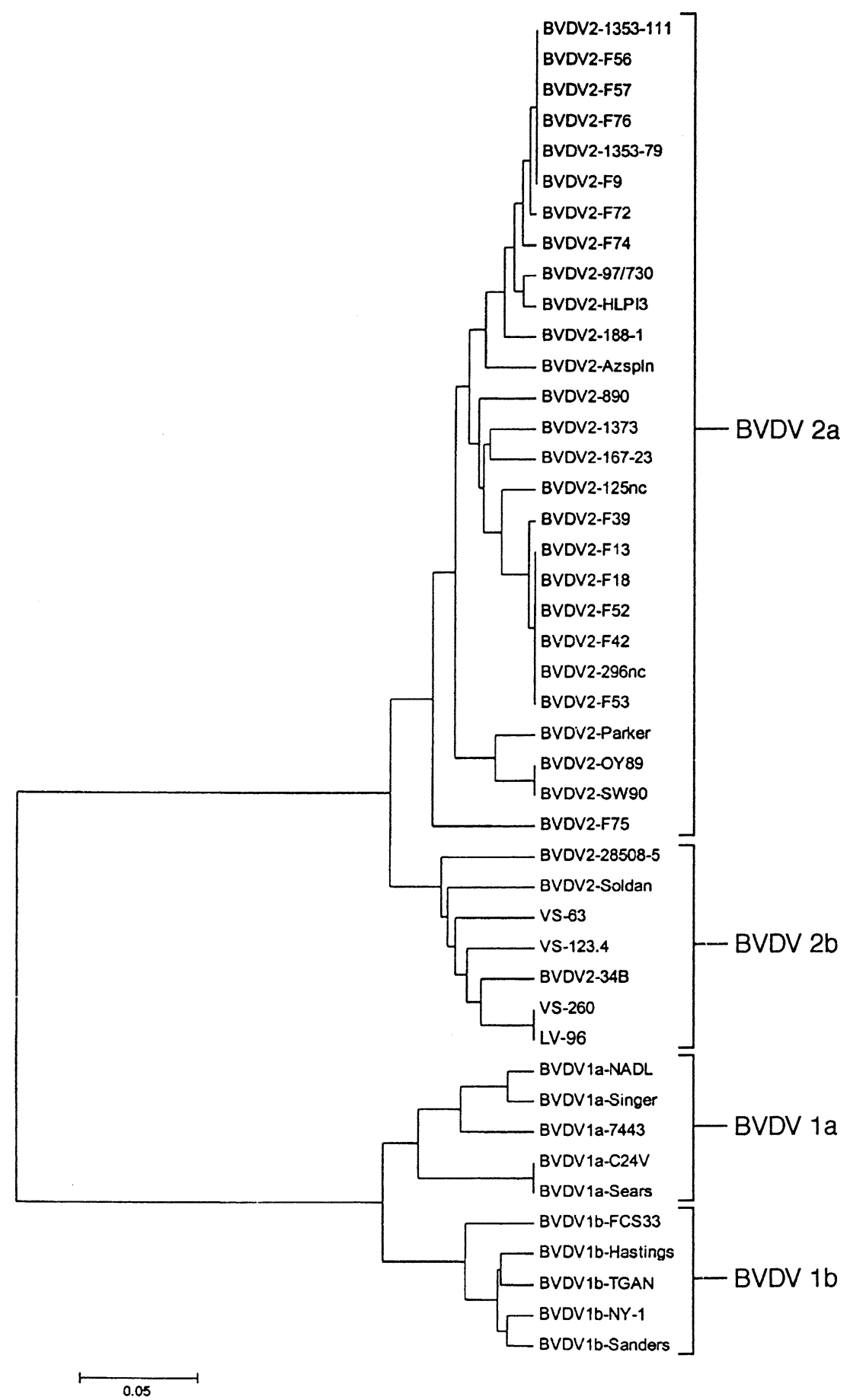

Fig. 1. Comparison of 5'UTR sequences from bovine viral diarrhea viruses type 2 (BVDV2) from South and North America, Europe and Asia. The four Brazilian BVDV2 strains were compared to 30 BVDV2 from South and North America, Europe and Asia, five BVDV1a and five BVDV1b strains. The unrooted phylogenetic tree (alignment by the ClustalW multiple alignment method, European Molecular Biology Laboratory, Heidelberg, Germany) was generated using the $p$-distance/Neighbor-Joining method (MEGA, version 1.02, Pennsylvania State University) and subjected to 500 bootstrap samplings. The scale bar represents 0.05 mutations per 100 sequence positions. 


$\begin{array}{lll}\text { Sequence } & 1 & \text { LV-96 (Ref. molecule) } \\ \text { Sequence } & 2 & \text { VS-260 } \\ \text { Sequence } & 3 & \text { VS-63 } \\ \text { Sequence } & 4 & \text { VS-123.4 } \\ \text { Sequence } & 5 & \text { BVDV2-SOLDAN } \\ \text { Sequence } & 6 & \text { BVDV2-34B } \\ \text { Sequence } & 7 & \text { BVDV2-28508-5 } \\ \text { Sequence } & 8 & \text { BVDV2-AZSPLN } \\ \text { Sequence } & 9 & \text { BVDV2-1373 } \\ \text { Sequence } 10 & \text { BVDV2-890 } \\ \text { Sequence } 11 & \text { BVDV2-167237 1 } \\ \text { Sequence } 12 & \text { BVDV2-OY89 } \\ \text { Sequence } 13 & \text { BVDV2-SW90 } \\ \text { Sequence } 14 & \text { BVDV2-97 730 } \\ \text { Sequence } 15 & \text { BVDV2-PARKER } \\ \text { Sequence } 16 & \text { BVDV2-125NC } \\ \text { Sequence } 18 & \text { BVDV1a-NADL } \\ \text { Sequence } 21 & \text { BVDV1b-NY-1 }\end{array}$

Homology

998

948

948

948

$95 \%$

938

898

878

$87 \%$

$88 \%$

898

898

908

878

$88 \%$

788

778

\section{GAAGTCGTCAGTGGTTCGACGCTCTGGCAATGGAAGAGCCTCGAGATGCC}

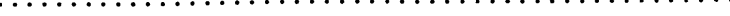

$\ldots \ldots \ldots \ldots$ А....................

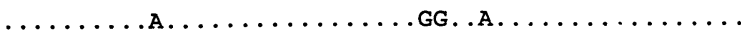

$\ldots \ldots \ldots \ldots \ldots \ldots$. $\ldots \ldots A$ CA.

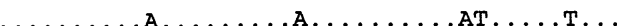

..................САT. .GCT..G.........

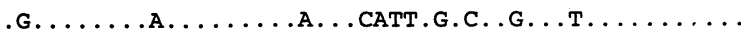

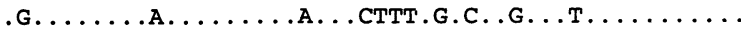

.G............... .САT. . . CATG... . . . . . .

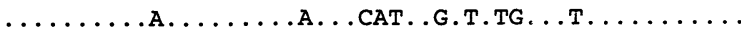

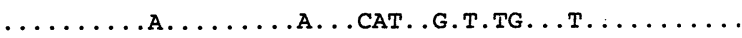

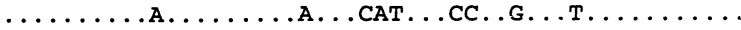

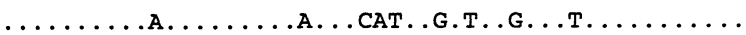

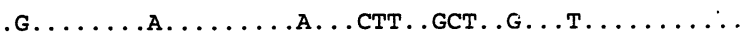

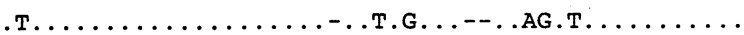

.T. . . . . . . . . . .
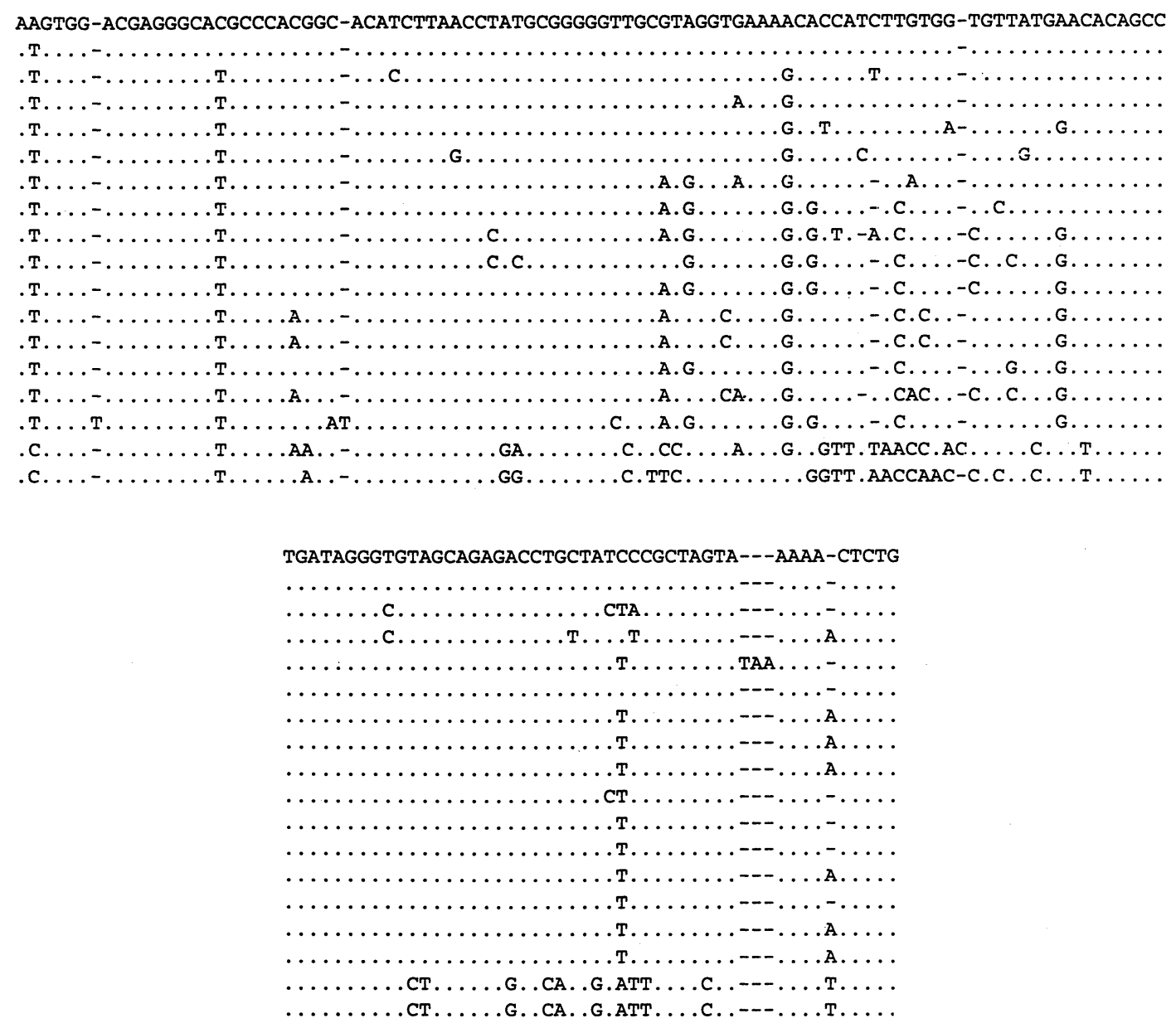

Fig. 2. Alignment of $5^{\prime} \mathrm{UTR}$ nucleotide sequences. Alignment of BVDV2 subgroup b (BVDV2b) sequences with sequences from BVDV2a, BVDV1a and BVDV1b strains. Sequences shown correspond to positions 190 through 374 of BVDV1a-SD-1. The reference molecule used for comparison was the genome of the Brazilian isolate LV-96. Dots represent identity of nucleotides. 
BVDV1b (Ridpath et al., 1994). Nevertheless, in both regions the South American isolates showed less base substitutions than the other BVDV2. A number of other scattered nucleotide differences were also observed across the $5^{\prime}$ UTR sequence (Fig. 2).

\subsection{Sequence analysis of the NS23 coding region}

To determine if the segregation of BVDV2 to two separate subgroups was real, an additional analysis was performed comparing the NS2/3 sequences from four Brazilian viruses and sequences available from North American BVDV2 isolates. The analysis compared a highly conserved sequence located between nt 6670 and 7166 of the NS2/3 coding region. Analysis of this sequence also segregated the Brazilian BVDV2 to a separate group (Fig. 3). The sequence homology between the two subgroups $(86.3 \%)$, was higher than the homology in the $5^{\prime}$ UTR $(81.7 \%)$, with mean sequence homologies of 91 and $87.2 \%$ within the BVDV2b and BVDV2a groups, respectively. Pairwise comparisons revealed homologies ranging from 92 to $99 \%$ within the BVDV2b group and of $87-88 \%$ between the reference sequence (LV-96) and strains from the BVDV2a group. In contrast with the 5'UTR, alignment of the NS2/3 sequences revealed that nucleotide differences were distributed throughout the region (Fig. 4).
Nonetheless, several subgroup-specific nucleotide substitutions may be observed upon examination of these sequences (Fig. 4). The sequences corresponding to the $5^{\prime} \mathrm{UTR}$ and NS2/3 of Brazilian BVDV2 were recently submitted to GenBank (Accession No.: AF410787 through AF410790 and AY056470 through AY056473, respectively).

\section{Discussion}

The BVDV1 genotype has been segregated into two to 11 subgenotypes (Pellerin et al., 1994; Vilcek et al., 2001). However, previous studies have not identified discrete subgenotypes of BVDV2. In this study, the phylogenetic comparison of BVDV2 from South America, North America, Europe and Asia suggests that there are at least two distinct subgroups within the BVDV2 genotype. Four Brazilian BVDV2s isolated between 1996 and 1998, one Brazilian BVDV2 isolated approximately 10 years earlier (Canal et al., 1998), a BVDV2 isolated from Argentina and one North American isolate (BVDV2 28508-5) clustered into the same subgroup. The remaining 23 North American (US and Canada) BVDV2 analyzed in this study grouped with two European BVDV2 and two Asian (Japan) BVDV2 isolates in a second subgroup. This genetic segregation was supported by phylogenetic analysis of two

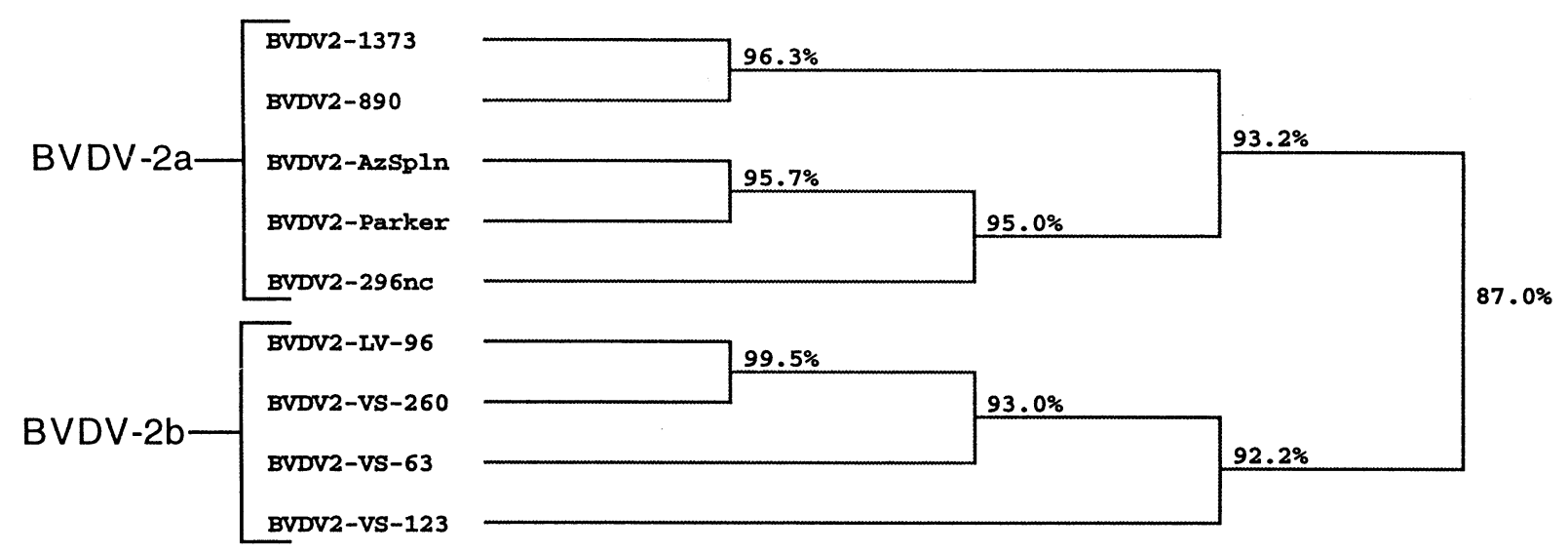

Fig. 3. Phylogenetic analysis of NS2/3 coding region sequences. Dendrograms were generated using the Higgins-Sharp sequence alignment option, of the MacDNASIS Sequence Analysis software package. The calculated matching percentages are indicated at each branch point. 


$\begin{array}{lll}\text { Sequence } & 1 & \text { LV-96 (Ref. molecule) } \\ \text { Sequence } & 2 & \text { VS-260 } \\ \text { Sequence } & 3 & \text { VS-63 } \\ \text { Sequence } & 4 & \text { VS-1234 } \\ \text { Sequence } & 5 & \text { BVDV2-AZSPLN } \\ \text { Sequence } & 6 & \text { BVDV2-1373 } \\ \text { Sequence } & 7 & \text { BVDV2-890 } \\ \text { Sequence } & 8 & \text { BVDV2-PARKER }\end{array}$

\begin{tabular}{|c|c|}
\hline omology & AGAGTAGGAAGGGTTAAGCCAGGAAGGTACTACAGAAGCCAGGAAACGG \\
\hline $\begin{array}{l}998 \\
938 \\
928 \\
878 \\
888 \\
878 \\
878\end{array}$ & - \\
\hline
\end{tabular}

CTACTGGGTCAAAGGATTATCACTACGACCTGCTGCAGGCTCAAAGGTATGGAATAGAAGATGGAATCAACGTGACAAAGTCGTTCAGGGAGATGAACTA А.

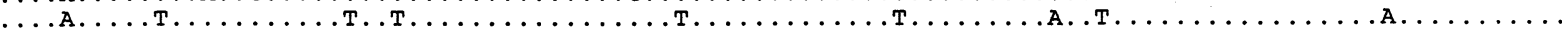

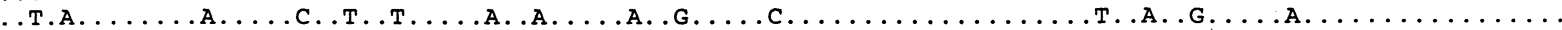

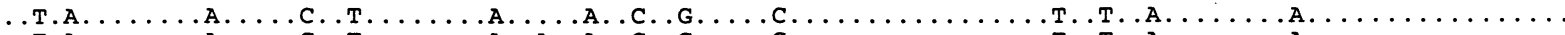

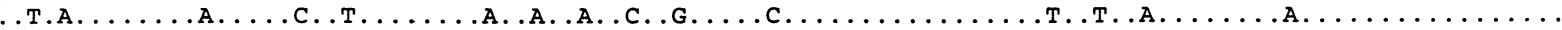
.T.A..........T.T...A.A.....G.

TGACTGGAGTCTTTATGAAGAAGATAGCCTAATGATAACCCAACTCGAGGTCCTCAATAACCTCCTTATATCAGAAGACCTGCCGGCCGCAGTAAAAAAT …

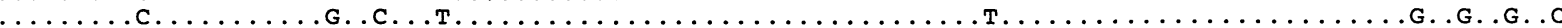

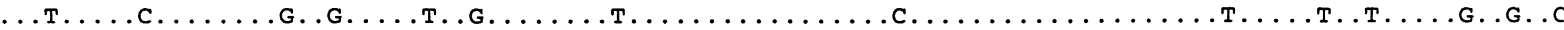

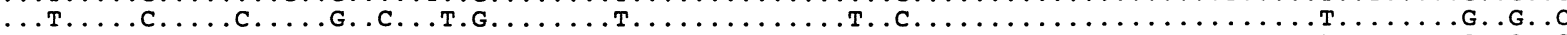

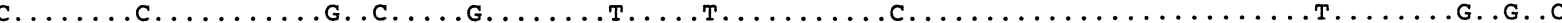

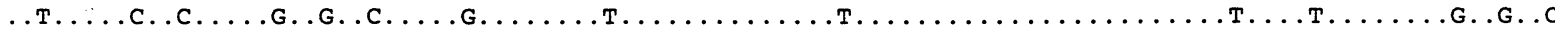
ATCATGGCCCGACCGACCACCCAGAACCTATACAACTAGCTTATAACAGTTATGAAAACCAAGTACCAGTGCTGTTTCCAAAAATTAAAAATGGGGAGG $\ldots$
$\cdots$
$\cdots$
$\cdots$ TTATGAAAACCAAGTACCAGTGCTGTTTCCAAAAATTAAAAATGGGGAGGTGACAGACAGTTATGAGAATTACACATACCTCAATGCAAGAAAACTAGGG

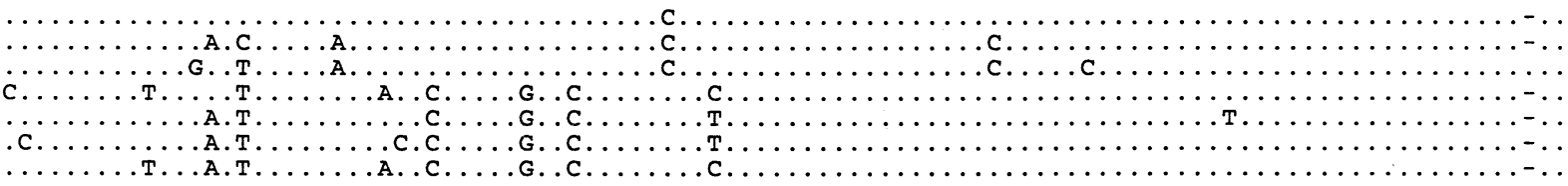
AGAGGATGTACCGGCATACGTGTACGCCACGGGAGGTGAGGATCTA

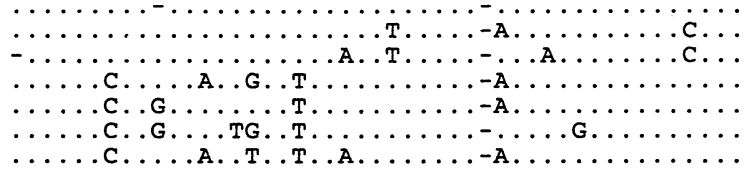

Fig. 4. Comparison of the NS2/3 sequences from BVDV2 from Brazil and North America. Sequences correspond to nucleotides 6670-7166 of the BVDV1a-SD-1 strain. The reference molecule used for comparison was the genome of the Brazilian isolate LV-96. Dots represent identity of nucleotides.

separate regions of the viral RNA genome, i.e. the 5'UTR and the NS2/3 coding region. The 5'UTR sequence differences observed between the two subgroups of BVDV2 are larger than those observed between BVDV1a and BVDV1b (Pellerin et al., 1994) and than those used to segregate BVDV1 into 11 subgenotypes (Vilcek et al., 2001). In keeping with the terminology used for BVDV1 isolates, we suggest that these two subgroups be referred to as BVDV2a (subgroup containing the
European, Asian and the majority of the North American isolates) and BVDV2b (subgroup containing the six South American isolates and one North American isolate).

After the initial identification of BVDV2 in the late 1980s, molecular methods, such as nucleic acid hybridization, PCR and nucleotide sequencing followed by phylogenetic analysis, have been used to differentiate and to group BVDV field isolates (Ridpath et al., 1993; Vilcek et al., 1994; 
Ridpath and Bolin, 1998). Since then, phylogenetic analysis of hundreds of BVDV isolates have been performed by many laboratories (Wolfmeyer et al., 1997; Bolin and Ridpath, 1998; Canal et al., 1998; Vilcek et al., 1994, 2001). In many cases, however, the practical consequence of the genetic grouping has not been easily demonstrated. The practical significance of BVDV genotyping would be reinforced as the grouping schemes correlate with phenotypic traits (i.e. antigenic, pathogenic/ virulence), epidemiology (Ridpath and Bolin, 1998; Ridpath et al., 2000) and studies of genetic divergence.

The genetic subdivision of BVDV into two genotypes (BVDV1 and BVDV2) based on sequence analysis of the $5^{\prime} \mathrm{UTR}$ is supported by monoclonal antibody binding and by cross-neutralization studies, likely reflecting antigenic differences in the E2 envelope glycoprotein (Pellerin et al., 1994; Ridpath et al., 1994; Van Rijn et al., 1997). Thus, the genetic/antigenic segregation of BVDV into two genotypes has obvious implications for diagnosis and control by vaccination.

Attempts to definitively correlate the BVDV1 versus BVDV2 genotypic segregation with virulence have been less conclusive. Initially thought to be new and invariably highly virulent viruses, BVDV2 have been frequently isolated from a variety of clinical or subclinical conditions other than cattle with acute BVD and hemorrhagic syndrome (Carman, 1995; Wolfmeyer et al., 1997; Bolin and Ridpath, 1998; Fulton et al., 2000). Moreover, data gathered from extensive genotyping of BVDV field isolates indicates that avirulent BVDV2 do exist and may even predominate over BVDV1 in the field (Ridpath and Neill, 1998; Ridpath et al., 2000). The South American BVDV2 isolates further exemplify the variety of clinical conditions that may be associated with this genotype. These viruses have been isolated from different sources including acute BVD with hemorrhagic signs (VS-260, Soldan), chronic BVD (LV-96) and healthy fetuses (34B, VS-123.4 and VS-63) (Flores et al., 2000).

Correlation between genetic subgrouping of BVDV1 and antigenic differences might exist (Ridpath et al., 2000), yet it has not been easily demonstrated by Mab-binding and/or cross-neu- tralization (Dekker et al., 1995; Paton et al., 1995; Vilcek et al., 2001). Rather, genetic analysis of BVDV1 isolates from Europe and North America suggests that segregation of BVDV1 into subgenotypes seems to be more correlated with geographical location (Van Rijn et al., 1997; Vilcek et al., 2001). In our study, at least three of the Brazilian viruses (VS-123.4, VS-260 and LV-96) showed a distinct pattern of monoclonal antibody binding when compared to the prototype BVDV2 890. Such differences, however, were not observed for isolate VS-63, which showed a pattern of Mab recognition similar to BVDV 890. Our data suggests that phylogenetic grouping of BVDV may be useful in evolutionary and epidemiological studies.

The subgrouping of BVDV2 may correlate with the geographical origin of these viruses. The majority of South American isolates characterized to date segregate to the same subgenotype. While one North American BVDV2 segregated to the same subgenotype the majority of strains (27 out of 28) characterized in this study segregated to a different subgenotype.

These data have important implications regarding the origin and emergence of the BVDV2 genotype. Initially, some researchers considered the BVDV2 genotype to be a recent variant of the BVDV1 genotype. There was even discussion that the BVDV2 genotype arose in the US in the 1980s as a result of selective pressure applied by vaccination programs. However, if the BVDV2 genotype arose due to this type of selective pressure, one would expect that the majority of sequence differences would be observed in sequences that code for structural proteins. This is not what is observed. Differences are found throughout the genome (Ridpath et al., 2000). These data also argue against a recent emergence of the BVDV2 genotype. BVDV2 have existed long enough to diverge into distinct subgroups and to establish geographic variants. There is no evidence to suggest that mutation rates differ between BVDV1 and BVDV2 isolates. Comparable divergence among BVDV1 and BVDV2 strains suggest that BVDV2 strains have been in nature as long as BVDV1 isolates. Thus, BVDV2 most likely represent a newly identified group of viruses rather than a new group of viruses. 
In summary, phylogenetic analysis of BVDV2 isolates from various geographical locations may be grouped into subgenotypes. The differences reported here are larger than those used to segregate BVDV1 subgenotypes. Based on these data, we suggest that BVDV2 may be thereafter subgenotyped into BVDV2a and BVDV2b. Whether this subdivision correlates exclusively with the geographical location or may be associated with other phenotypic and epidemiological traits awaits genotyping of a larger number of BVDV from diverse locations and associated with a variety of clinical conditions.

\section{Acknowledgements}

Isolate LV-96 was provided by Dr Valéria Moojen (Faculdade de Veterinária, Universidade Federal do Rio Grande do Sul, RS, Brazil). We thank Margaret Walker (NADC/ARS/USDA) for technical support.

\section{References}

Baker, J.C., 1995. Clinical manifestations of bovine viral diarrhea infection. Vet. Clin. North Am. 11 (3), 425-445.

Bolin, S.R., Ridpath, J.F., 1998. Prevalence of bovine viral diarrhea virus genotypes and antibody against those viral genotypes in fetal bovine serum. J. Vet. Diagn. Invest. 10 (2), 135-139.

Canal, C.W., Strasser, M., Hertig, C., Masuda, A., Peterhans, E., 1998. Detection of antibodies to bovine viral diarrhea virus (BVDV) and characterization of genomes of BVDV from Brazil. Vet. Microbiol. 63, 85-97.

Carman, S., 1995. Typing of Ontario BVD virus isolates from 1981 to 1994. Ontario Ministry of Agriculture, Food and Rural Affairs, May, 1995.

Carman, S., Van Dreumel, T., Ridpath, J., Hazlett, M., Alves, D., Dubovi, E.J., Tremblay, R., Bolin, S.R., Godkin, A., Anderson, N., 1998. Severe acute bovine viral diarrhea (BVD) in Ontario, 1993-1995. J. Vet. Diagn. Invest. 10 (1), 27-35.

Collett, M.S., Larson, R., Belzer, S.K., Retzel, E., 1988. Molecular cloning and nucleotide sequence of the pestivirus bovine viral diarrhea virus. Virology 165, 191-199.

Corapi, W., French, T., Dubovi, E., 1989. Severe thrombocytopenia in young calves experimentally infected with noncytopathic bovine viral diarrhea virus. J. Virol. 63, 3934-3943.
Dekker, A., Wensvoort, G., Terpstra, C., 1995. Six antigenic groups within the genus pestivirus as identified by crossneutralization assays. Vet. Microbiol. 47, 317-329.

Deng, R., Brock, K.V., 1992. Molecular cloning and nucleotide sequence of a pestivirus genome, noncytopathic bovine viral diarrhea virus strain SD-1. Virology 191, 867-869.

Deng, R., Brock, K.V., 1993. 5 and 3 untranslated regions of pestivirus genome: primary and secondary structure analyses. Nucleic Acids Res. 21 (8), 1949-1957.

Flores, E.F., Gil, L.H.V.G., Botton, S.A., Weiblen, R., Ridpath, J.F., Kreutz, L.C., Pilati, C., Driemeyer, D., Moojen, V., Wendelstein, A.C., 2000. Clinical, pathological and antigenic aspects of bovine viral diarrhoea virus (BVDV) type 2 isolates identified in Brazil. Vet. Microbiol. 77, $175-183$.

Francki, R., Fauquet, C., Knudson, D., Brown, F., 1991. Classification and nomenclature of viruses. Wien, New York: Springer-Verlag. Fifth Report of the International Committee on Taxonomy of Viruses (ICTV). Arch. Virol. 2, S223-S427.

Fulton, R.W., Saliki, J.T., Confer, A.W., Burge, L.J., d'Offay, J.M., Helman, R.G., Bolin, S.R., Ridpath, J.F., Payton, M.E., 2000. Bovine viral diarrhea virus cytophatic and noncytophatic biotypes and type 1 and 2 genotypes in diagnostic laboratory accessions: clinical and necropsy samples from cattle. J. Vet. Diagn. Invest. 12 (1), 33-38.

Gil, L.H.V.G., Botton, S.A., Odeon, S.A., Weber, L., Weiblen, R., Ridpath, J.F., Flores, E.F., 1998. Genotypic analysis of South American isolates of bovine viral diarrhea virus. In: Simpósio Internacional sobre Herpesvírus Bovino (tipo 1 e 5) e Vírus da Diarréia Viral Bovina (BVDV), p. 171.

Moennig, V., Liess, B., 1995. Pathogenesis of intrauterine infections with bovine viral diarrhea virus. Vet. Clin. North Am. 11 (3), 477-487.

Nagai, M., Sato, M., Nagano, H., Pang, H., Kong, X., Murakami, T., Ozawa, T., Akashi, H., 1998. Nucleotide sequence homology to bovine viral diarrhea virus 2 (BVDV2) in the 5 untranslated region of BVDVs from cattle with mucosal disease or persistent infection in Japan. Vet. Microbiol. 60 (2-4), 271-276.

Paton, D.J., Sands, J.J., Lowings, J.P., Smith, J.E., Ibata, G., Edwards, S., 1995. A proposed division of the pestivirus genus using monoclonal antibodies, supported by crossneutralization assays and genetic sequencing. Vet. Res. 26, 92-109.

Pellerin, C., Van Den Hurk, J., Lecomte, J., 1994. Identification of a new group of bovine viral diarrhea virus strains associated with severe outbreaks and high mortalities. Virology 203 (2), 260-267.

Ridpath, J.F., Bolin, S.R., 1998. Differentiation of types 1a, $1 \mathrm{~b}$ e 2 bovine viral diarrhoea virus (BVDV) by PCR. Mol. Cell Probes 12 (2), 237-243.

Ridpath, J.F., Neill, J.D., 1998. Characterization of virulent and avirulent BVDV from the type 2 genotype. In: Proceedings of the Seventeenth Annual Meeting of the American Society for Virology, p. 162. 
Ridpath, J.F., Bolin, S., Dubovi, E., 1993. Comparison of nucleic acid hybridization and nucleic acid amplification using conserved sequences from de 5 noncoding region for detection of bovine viral diarrhea virus. J. Clin. Microbiol. 31, 986-989.

Ridpath, J.F., Bolin, S., Dubovi, E., 1994. Segregation of bovine viral diarrhea virus into genotypes. Virology 205, 66-74.

Ridpath, J.F., Neill, J.D., Frey, M., Landgraf, J.G., 2000. Phylogenetic, antigenic and clinical characterization of type 2 BVDV from North America. Vet. Microbiol. 77, 145155.

Van Rijn, P.A., Van Gennip, H.G.P., Leendertse, C.H., Bruschke, C.J.M., Paton, D.J., Moormann, R.J.M., van Oirschot, J.T., 1997. Subdivision of the pestivirus genus based on envelope glycoprotein E2. Virology 231, 337-348. Vilcek, S., Herring, A.J., Herring, J.A., Nettleton, P.F., Lowings, J.P., Paton, D.J., 1994. Pestivirus isolated from pigs, cattle and sheep can be allocated into at least three genogroups using polymerase chain reaction and restriction endonuclease analysis. Arch. Virol. 136 (3-4), 309-323.

Vilcek, S., Paton, D.J., Durkovic, B., Strojny, L., Ibata, G., Moussa, A., Loitsch, A., Rossmanith, W., Veja, S., Scicluna, M.T., Paif, V., 2001. Bovine viral diarrhea virus genotype 1 can be separated into at least eleven genetic groups. Arch. Virol. 146 (1), 99-115.

Wolfmeyer, A., Wolf, G., Beer, M., Strube, W., Hehnen, H.-R., Schmeer, N., Kaaden, O.R., 1997. Genomic (5 UTR) and serological differences among German BVDV field isolates. Arch. Virol. 142, 2049-2057. 